\title{
A COVID 19 E AS POLÍTICAS EUROPEIAS SOBRE DIREITOS HUMANOS*
}

\section{LA COVID 19 Y LAS POLÍTICAS EUROPEAS SOBRE LOS DERECHOS HUMANOS}

\author{
Carlos Maria Romeo Casabona ${ }^{1}$ \\ Universidade do País Basco (UPV/EHU)
}

\begin{abstract}
Resumo:
Admite-se sem discussão que a pandemia do coronavírus vem afetando principalmente a saúde pública, como bem jurídico coletivo, mas também sabemos que tem custado milhares de vidas e danos à saúde individual de milhões de pessoas. Dada a gravidade que a doença covid 19 vem adquirindo, também é apresentada de uma perspectiva mais básica, embora ainda seja muito remota, que pode afetar também a espécie humana, a sua sobrevivência. As restrições e privações da liberdade de movimentação ou de circulação vêm afetando não só esta, mas também uma longa lista de direitos dos cidadãos, muitos dos quais fundamentais. O retorno à normalidade, erroneamente denominado por alguns "nova normalidade”, apresenta complexidades próprias, mas é preciso retornar à situação anterior, ao início da pandemia, de pleno exercício dos direitos dos cidadãos, ainda que de maneira gradual e acompanhando o ritmo da evolução da pandemia.
\end{abstract}

Palavras-chave:

saúde pública, espécie humana, direitos fundamentais, cooperação entre os Estados, Grupo Europeu de Ética, Conselho da Europa, Comissão Europeia, nova normalidade, normalidade.

\section{Resumen:}

Es aceptado sin discusión que la pandemia del coronavirus está afectando de forma primaria a la salud pública, como bien jurídico colectivo, pero también sabemos que ha costado miles de vidas y daños a la salud individual de millones de personas. Dada la gravedad que ha ido adquiriendo la enfermedad covid 19, también se plantea desde una perspectiva más básica, aunque todavía sea muy remota, que puede afectar asimismo a la especie humana, a su supervivencia. Las restricciones y privaciones de la libertad ambulatoria o de movimientos ha afectado no solo a ésta sino también a una larga lista de derechos de los ciudadanos, no poco de ellos fundamentales. La vuelta a la normalidad, incorrectamente llamada por algunos "nueva normalidad”, presenta sus propias complejidades, pero hay que volver a la situación anterior al inicio de la pandemia, de pleno ejercicio de los derechos de los ciudadanos, aunque sea de forma gradual y acompasada a la evolución de la pandemia.

Palabras clave:

salud pública, especie humana, derechos fundamentales, cooperación entre los Estados, Grupo Europeo de Ética, Consejo de Europa, Comisión Europea, nueva normalidad, normalidad.

\section{A EVOLUÇÃO DO BEM JURÍDICO PROTEGIDO ANTE A PANDEMIA COVID- 19: DA SAÚDE PÚBLICA À PROTEÇÃO DA ESPÉCIE HUMANA}

Ao longo do nascimento e expansão da pandemia causada pelo vírus SARS-CoV-2, considerou-se sem discussão que o bem jurídico sujeito à proteção perante o vírus é a saúde pública. Nada pode ser contestado a esta posição, que recebeu aceitação geral, e em particular entre os profissionais de saúde, autoridades de saúde e juristas. Ou seja, um bem jurídico de natureza coletiva e, portanto, supra-individual. Além disso, costuma ser considerado um bem

\footnotetext{
* Este trabalho é realizado no âmbito do financiamento do Governo Basco para Grupos de Pesquisa do Sistema Universitário Basco (IT1066-16).

${ }^{1}$ Dr. iur., Dr. med. Carlos María Romeo Casabona, Catedrático de Derecho Penal, Investigador Principal, G.I. Cátedra de Derecho. Orcid: https://orcid.org/0000-0001-5421-7115

Tradução: Maria de Fátima Freire de Sá (PUC Minas). Orcid: https://orcid.org/0000-0002-3485-4923
} 
jurídico intermediário, no sentido de que embora a saúde pública seja o interesse imediato protegido, é na verdade um bem jurídico instrumental, por meio do qual se trata, em última instância, de proteger a vida e a saúde das pessoas, ou seja, de indivíduos específicos.

A enorme expansão global que a doença COVID-19 experimentou, com vários milhões de infectados, muitos dos quais desenvolveram a doença e mais de um milhão de pessoas morreram, por enquanto, sugere que a saúde pública pode falhar como um bem jurídico protegido. Se, apesar das medidas de prevenção e tratamento adotados nos diversos países que mais sofreram com a doença, com maior sucesso ou fracasso, não foi possível evitar a catástrofe de tantos enfermos e falecidos, também não o foi a contenção da propagação para muitas partes do planeta, embora algumas áreas ainda estejam livres de contágio, e isso felizmente, ainda que a infraestrutura seja deficiente para atender às demandas diárias de saúde de suas populações, significa que pode ser necessário identificar outro bem jurídico ainda mais relevante.

Com isso entendemos a sobrevivência da espécie humana, a sua proteção como um bem jurídico protegido de natureza autônoma². E, por sua vez, pode apresentar várias facetas. Uma delas seria a manutenção da espécie humana com as características biológicas essenciais que a identificam e a diferenciam de outras espécies, como consequência, por exemplo, da aplicação de modernas biotecnologias de replicação de DNA ou da mais recente edição de genes. As espécies seriam conservadas, mas com características muito diferentes. O que realmente pode vir a ser considerado um perigo para a sobrevivência humana em relação ao coronavírus seria a própria existência do ser humano, sua permanência no planeta. Não podemos afirmar neste momento que este perigo seja real ou pareça iminente, visto que foram criadas infraestruturas e foram armazenados produtos médicos aparentemente suficientes para prevenir surtos hipotéticos, mas uma nova expansão descontrolada, ou outra semelhante causada por um patógeno diferente, em outras áreas do planeta até agora imunes, poderia atingir uma dimensão qualitativamente diferente, muito mais séria, que é o que esta reflexão quer identificar.

Portanto, basta agora advertir esta hipótese de trabalho diante de uma grande expansão da doença COVID-19 ou outra de capacidade semelhante.

\footnotetext{
2 Não partilhamos a posição de quem considera que a espécie humana deve ser reconhecida como titular de direitos. Seria necessário perguntar em que consistiriam esses direitos (não se consegue ver outros interesses diferentes à sobrevivência da espécie humana ou a garantia da integridade da identidade de sua espécie), contra quem ou o que seriam exercidos (contra os mesmos seres humanos, ou outros seres vivos?) e por quem (não a própria espécie, que não tem e não deve ser reconhecida como personalidade; quem a representaria então?). No entanto, a propriedade dos direitos da espécie humana é defendida em A Pisanò (ed.), Se la specie umana sia titolare di diritti, Edizione Scientifiche Italiane, Napoli, 2007, cisim (165 ff.).
} 
E se falamos da sobrevivência e da proteção da espécie humana, será mais fácil entender a necessidade inalienável de cooperação dos Estados para enfrentar a atual pandemia em um marco de solidariedade interestadual e respeito aos direitos humanos.

Esta cooperação deve ocorrer ao mais alto nível, de forma a garantir uma eficiência mínima, porém relevante. Em outras palavras, compreende o envolvimento e a ação direta de organizações governamentais internacionais de alcance universal. Em primeiro lugar, em razão da matéria, a OMS, a quem caberia tomar iniciativas para promover a contenção da pandemia em questão (não só a provocada mais recentemente pelo SARS-CoV-2; temos outros infelizes e graves antecedentes); promover pesquisas coordenadas em relação às doenças contagiosas mais conhecidas, especificamente as de origem viral, buscando conhecer os aspectos comuns das etiologias das doenças virais que se têm manifestado com certa agressividade na espécie humana, seus possíveis saltos interespécies, ambientes favoráveis para estes últimos, germinação, desenvolvimento e evolução dessas pandemias, orientações médicas para a prevenção de contágios, vacinas e tratamentos disponíveis ou que necessitem de novos recursos de vários tipos (por exemplo, moléculas ou princípios ativos que possam gerar a obtenção e introdução de novos fármacos), e outros aspectos sócio-sanitários em escala mundial, sem abandonar os grupos populacionais à sua sorte (falta de recursos, territórios, países).

\section{AS OBRIGAÇÕES DOS ESTADOS DIANTE DA PANDEMIA COVID-19: SOLIDARIEDADE ENTRE ELES E RESPEITO PELOS DIREITOS DOS CIDADÃOS}

São inúmeros os atos de solidariedade que conhecemos no decorrer da pandemia provocada pelo vírus SARS-CoV-2, tanto de cidadãos como de alguns profissionais que foram além do estrito cumprimento das suas obrigações profissionais, como por exemplo, foi verificado com profissionais de saúde, mas também por agentes das forças de segurança, exército e outros. Alguns dos quais contraíram e desenvolveram a doença COVID-19 e entre eles não poucos com resultados fatais.

Como foi salientado pelo Grupo Europeu de Ética na Ciência e nas Novas Tecnologias $(\mathrm{EGE})^{3}$, órgão consultivo independente do Colégio de Comissários Europeus, a solidariedade torna-se um conceito muito pobre se apenas a aplicarmos àqueles que estão próximos de nós

\footnotetext{
${ }^{3}$ European Group in Science and New Technologies (EGE), Statement on European Solidarity and the Protection of Fundamental Rights in the COVID-19 Pandemic, 4th April 2020. Como membro deste Grupo e participante na redação deste documento (CM Romeo Casabona), então seguimos de perto as posições do mesmo.
} 
ou surge com condições e negociações. É mais poderoso e significativo quando se estende sem reservas também àqueles que são diferentes. Segundo a EGE, é mais importante do que nunca nesta difícil situação manter uma forma de solidariedade que inclua a todos, que reconheça que o respeito é devido a todos e que não é exclusivo de quem vive na nossa cidade, região ou país ${ }^{4}$.

De acordo com os critérios deste órgão consultivo europeu, a atual pandemia deve ser utilizada para promover a solidariedade a nível europeu e global. Consequentemente, os Estados se preocupam em adotar práticas solidárias entre si, pensando no benefício de todos os seus cidadãos. Essa solidariedade deve se manifestar em ações concretas, como a troca leal e a partilha de informações, experiências, inovações e recursos. Os governos dos Estados devem ser transparentes em suas tomadas de decisão, fortalecer a ciência e a pesquisa abertas e cooperar internacionalmente ${ }^{5}$.

Quando os cidadãos são solicitados a confiar naqueles em posições de conhecimento e poder e a aceitar suas regras de governo, o respeito pelos princípios democráticos, a transparência, a responsabilidade e o Estado de Direito são mais importantes do que nunca. A pandemia também é um desafio para as noções individualistas e nacionalistas de segurança, saúde e bem-estar, conclui a $\mathrm{EGE}^{6}$.

A solidariedade entre os Estados, especialmente, mas não só, se fizerem parte de uma organização supranacional, como a União Europeia, implica em nossa opinião:

- Assumir como ponto de referência partilhado entre os Estados o conjunto de valores que informam os instrumentos jurídicos comuns, conforme evidenciado por um dos instrumentos jurídicos mais relevantes da UE, a Carta dos Direitos Fundamentais ${ }^{7}$ :

\footnotetext{
“Consciente do seu patrimônio espiritual e moral, a União assenta nos valores indivisíveis e universais da dignidade humana, da liberdade, da igualdade e da solidariedade, e assenta nos princípios da democracia e do Estado de Direito. Ao instituir a cidadania da União e ao criar um espaço de liberdade, segurança e justiça, coloca a pessoa no centro das suas ações”.
}

\footnotetext{
${ }^{4}$ EGE, Statement on European Solidarity and the Protection of Fundamental Rights in the COVID-19 Pandemic.

${ }^{5}$ EGE, Statement on European Solidarity and the Protection of Fundamental Rights in the COVID-19 Pandemic.

${ }^{6}$ EGE, Statement on European Solidarity and the Protection of Fundamental Rights in the COVID-19 Pandemic.

${ }^{7}$ V. Carta de los Derechos Fundamentales de la Unión Europea (Nice, 2000, e substituído pela Carta 2010/C 83/02, uma vez que o Tratado de Lisboa entrou em vigor).
} 
- Eliminar ações competitivas e descoordenadas entre os estados comunitários para a obtenção de medicamentos e produtos de saúde necessários para combater a pandemia ou prevenir sua propagação.

- Incentivar a colaboração de indústrias e cientistas de vários países na pesquisa para obtenção de vacinas, medicamentos e outros tratamentos mais específicos para a doença COVID-19. Para a sua introdução no mercado e que cheguem a todas as pessoas em situação de risco (idosos, profissionais de saúde, agentes dos órgãos e forças de segurança) será necessário chegar a acordos entre a indústria e os governos para fixar preços razoáveis disponíveis aos cidadãos, independentemente da sua situação econômica individual.

- Agir de forma coordenada na tomada de decisões que possam afetar os cidadãos de outros estados, em particular em relação às restrições ao movimento transfronteiriço (medidas de passagem das fronteiras, em particular dentro do espaço Schengen) ou com a flexibilização ou extinção, de forma a garantir a semelhança das decisões e práticas de segurança, sem prejuízo do atendimento das necessidades específicas de cada estado.

- Acesso a recursos econômicos e financeiros por parte dos países mais gravemente afetados pela pandemia para fazer frente à crise econômica gerada pela própria pandemia, ou seja, derivada das decisões que devem ser tomadas contra ela e que possam ter impacto direto na atividade produtiva ou no mercado de trabalho, entre outros. Será necessário deixar para outros fóruns a discussão sobre o melhor ou o pior manejo do mesma nas ações preventivas de contágios e no tratamento de pacientes, do que, aparentemente, praticamente nenhum estado foi poupado. A chuva é para todos.

\section{SAÚDE PÚBLICA CONFRONTADA COM OS DIREITOS HUMANOS}

A necessidade urgente de deter a rápida expansão do coronavírus, com capacidade de contágio ou transmissão até agora desconhecida, obrigou os poderes públicos dos diversos países a tomarem medidas, em muitas ocasiões drásticas, que afetaram diretamente direitos fundamentais e liberdades públicas dos cidadãos ${ }^{8}$.

\footnotetext{
${ }^{8}$ V. em relação às medidas sanitárias, CM Romeo Casabona (Coord.) / A Urruela Mora (co-editores) et al. (2020). Relatório do Ministério da Saúde sobre aspectos éticos em situações de pandemia: SARS-CoV-2, Ministério da Saúde, Madrid, 2 de abril de 2020; os mesmos, Stratégie de santé publish face au Covid-19 mise en éuvre par l'Espagne, Revue Droit \& Santé, nº 96, 2020, 549 et seq..
} 
As organizações internacionais que estão mais atentas à garantia da segurança dos direitos humanos afirmaram sem a menor reserva que as medidas adotadas para combater ou prevenir a pandemia devem satisfazer o requisito fundamental do respeito à dignidade humana e aos direitos humanos ${ }^{9}$.

O Convênio sobre Direitos Humanos e Biomedicina (Convênio de Oviedo), elaborado pelo Comitê de Bioética (DH BIO) do Conselho da Europa, aprovado pelo Comitê de Ministros e apresentado para assinatura dos estados por este órgão em 1997 na cidade espanhola de Oviedo $^{10}$, oferece um marco jurídico relevante e comprovado em direitos humanos e biomedicina, incluindo referências a situações de emergência (art. 8).

Da mesma forma, prevê a possibilidade de introduzir restrições ao exercício dos direitos e das disposições protetivas do próprio Convênio, exceções que visem à proteção de interesses supraindividuais ou coletivos, como, entre outros que sejam explicitamente mencionados, a saúde pública (art. 26).

Consequentemente, tanto o Direito Internacional como o interno dos Estados incluem a adoção de medidas excepcionais, e elas foram tomadas. $\mathrm{O}$ enfrentamento que pode surgir diante de uma pandemia tão grave e generalizada como a da COVID-19, que requer medidas, às vezes extremas, para combater e prevenir a propagação da pandemia foi exposto acima: ocorre entre saúde pública, por um lado, um interesse coletivo de especial relevância (bem jurídico) amparado por lei, que em uma expansão mundial descontrolada poderia levar ao bem jurídico da sobrevivência da espécie humana em relação a um cenário felizmente ainda hipotético; e os direitos das pessoas, por outro lado, que podem ter a categoria de direitos fundamentais, e outros interesses supra-individuais legítimos.

Em termos jurídicos, especificamente no âmbito do Direito Penal, ao qual este tipo de conflito é bastante familiar, o referido confronto é entendido como uma colisão de deveres entre interesses coletivos (dever de proteção da saúde pública) e interesses individuais e outros supra-individuais (dever de não prejudicar os direitos fundamentais e as liberdades públicas ou outros bens jurídicos coletivos) ${ }^{11}$. O conflito ocorre porque, quem é obrigado a cumprir os dois deveres, necessariamente infringirá um deles.

\footnotetext{
${ }^{9} \mathrm{~V}$. Conselho da Europa, Committee of Bioethics (DH BIO), Statement on human rights considerations relevant to the COVID-19 pandemic, Strasbourg, 14 April 2020.

${ }^{10}$ Convênio para a Proteção dos Direitos Humanos e da dignidade da ser humano com relação às aplicações da Biologia e da Medicina (Convênio relativo aos direitos humanos e biomedicina), feito em Oviedo em 4 de abril de 1997. Ratificado pelo Reino da Espanha em 23 de julho de 1999 (BOE 20 de outubro de 1999).

11 V. mais amplamente Vizueta Fernández, La legítima defensa y el estado de necesidad justificante, 234; Hernández Plasencia, El obrar en cumplimiento de un deber o en el ejercicio de un derecho, oficio o cargo. El consentimiento, 242 y s.
} 
A solução para esta colisão deve ser encontrada procedendo-se à preferência pelo cumprimento do dever que protege o interesse juridicamente preponderante na situação concreta, tendo em conta todos os interesses presentes em jogo ${ }^{12}$.

Mutatis mutandis, este critério também é válido para os poderes públicos: o poder legislativo ao aprovar ou validar normas restritivas de direitos; o executivo no cumprimento de tais disposições ou ao recorrer aos poderes que a lei lhe confere em tais situações de emergência); e os juízes devem resolver essas colisões de funções em suas sentenças de acordo com os critérios estabelecidos em lei.

\section{CRITÉRIOS INFORMADORES PARA ESTABELECER A PREVALÊNCIA DA SAÚDE PÚBLICA SOBRE OS DIREITOS FUNDAMENTAIS}

Começaremos por afirmar que as posições que têm sido mantidas por alguns setores inspirados no neoliberalismo extremo, foram totalmente desarmadas por esta pandemia, como já se percebeu em situações anteriores. Mesmo sob essa perspectiva, dificilmente viável no contexto social contemporâneo, apesar de seus esforços para prevalecer, especialmente no setor financeiro e em parte no setor empresarial, fenômenos tão graves para a saúde quanto esta pandemia mostram que nem mesmo as maiores fortunas estão isentas dos riscos gravíssimos para a saúde de qualquer cidadão, independentemente da sua situação econômica ou dos profundos problemas econômicos e financeiros que se avizinham. Por conseguinte, devemos reafirmar a legitimidade dos poderes públicos para tomar as medidas necessárias contra a pandemia, no âmbito da lei ${ }^{13}$. E é mesmo uma obrigação constitucional, como será lembrada a seguir, a ação intervencionista dos poderes públicos ${ }^{14}$.

A restrição de direitos fundamentais só pode ser admitida se forem atendidos certos pressupostos ou requisitos que sustentam a prevalência da saúde pública. Como exemplo, apontaremos algumas premissas.

\section{1. Pressupostos fáticos}

\footnotetext{
${ }^{12}$ Seguindo nisso a Vizueta Fernández, La legítima defensa y el estado de necesidad justificante, 233 y s.; JU Hernández Plasencia, El obrar en cumplimiento de un deber o en el ejercicio de un derecho, oficio o cargo. El consentimiento, no mesmo texto, 242 y s.

${ }^{13}$ Romeo Casabona (Coord.) / Urruela Mora (co-editores) et al., Informe del Ministerio de Sanidad sobre los aspectos éticos en situaciones de pandemia: el SARS-CoV-2, 5.

${ }^{14}$ Sobre este debate e contrário à abordagem liberal, Nuffield Council on Bioethics, Public Health: ethical issues, London, 2007, 13 y ss.
} 


\subsubsection{Uma situação de excepcionalidade}

A pandemia Covid 19 já provou ser assim, devido à sua rápida disseminação (elevado número de pessoas infectadas, que por sua vez podem transmitir o vírus a outras, principalmente se forem assintomáticas), devido à sua gravidade (altas taxas de mortalidade e necessidade de tratamento intensivo) e pela necessidade urgente de abundantes recursos de saúde de todos os tipos, incluindo profissionais de saúde treinados para lidar com este tipo de pandemia.

\subsubsection{Natureza temporária da situação}

A experiência de situações anteriores indica que essas crises de saúde pública, embora devastem a população, são de duração limitada. É mais duvidoso que sejam erradicadas, isto é, que desapareçam totalmente. O que se espera se não houver avanços definitivos na busca de soluções eficazes para prevenir a doença de forma que sua persistência seja pouco relevante, podemos nos encontrar em processos de cronificação da situação, podendo requerer a adoção de algumas medidas preventivas em geral dificilmente pesadas.

Consequentemente, as restrições aos direitos também devem ser temporárias ou transitórias.

Não é fácil prever a médio e longo prazo quando os direitos restringidos ou suprimidos deverão ser recuperados. Em nenhum caso deve-se esperar para conseguir a solução definitiva contra a pandemia, isto é, quando vacinas e tratamentos eficazes estiverem disponíveis; qualquer restrição só é legítima na medida e pela duração estrita e comprovadamente necessária para controlar a propagação da pandemia.

A consequência mais significativa que queremos sublinhar agora em relação a este pressuposto fático da temporalidade é, como será enfatizado a seguir, a do gradualismo, isto é, a eliminação ou redução gradual do alcance das medidas restritivas dos direitos dos cidadãos paralelamente ao desaparecimento, ou mais propriamente dito, ou limitação dos efeitos expansivos mais graves da pandemia. Como veremos a seguir, para o cumprimento satisfatório dessa trajetória de gradação, o princípio da proporcionalidade constitui uma referência de orientação do valor máximo.

\subsection{Princípios aplicáveis}




\subsubsection{A entrada em jogo de vários princípios compartilhados na cultura jurídica ocidental}

No contexto de uma pandemia, destacam-se os princípios da equidade (no acesso aos recursos necessários, inclusive vitais, de pessoas vulneráveis por sua idade, estado mental ou intelectual ou por qualquer outro motivo), não discriminação, solidariedade (de indivíduos, grupos humanos, territórios e Estados), justiça, proporcionalidade e transparência (na tomada de decisões, na divulgação e gestão da informação) ${ }^{15}$, entre outros, conforme Relatório do Ministério da Saúde Espanhol sobre os aspectos éticos da pandemia ${ }^{16}$.

Esses princípios só podem ser aplicados e adequadamente garantidos no Estado de Direito.

\subsubsection{O princípio da proporcionalidade}

Vale a pena prestar atenção ao princípio da proporcionalidade. É um instrumento jurídico de referência essencial na tomada deste tipo de decisões por parte das autoridades competentes e para contestá-las, se for caso disso, por partidos políticos, grupos parlamentares e outras entidades sociais legítimas, ou diretamente para criticá-las e rejeitá-las no exercício da liberdade de expressão. É assim que o TC o entende, ao apontar que o princípio da proporcionalidade é um princípio interpretativo e um instrumento jurídico de controle da constitucionalidade nas decisões dos poderes públicos que impedem ou restringem direitos fundamentais ${ }^{17}$.

A observância desse princípio acarreta três requisitos, como elementos de controle: as medidas restritivas de direitos devem ser estritamente necessárias, ou seja, adequadas à consecução do objetivo proposto; nenhum outro meio menos oneroso deve estar disponível; e a proporcionalidade em sentido estrito deve ser mantida, ponderando os benefícios buscados e a entidade dos danos previstos como prováveis. Este princípio aplica-se também à ponderação das sanções que venham a serem propostas ou impostas pelos agentes e integrantes das forças de segurança estaduais, regionais e locais, de acordo com as respectivas competências, neste caso também as marcadas pela lei de exceção.

\footnotetext{
${ }^{15}$ De acordo com o Deutscher Ethikrat, Solidarität und Verantwortung in der Corona-Krise, Berlim, 27 de março de 2020, 7 uma estratégia de informação sólida deve ser promovida: comunicação transparente e regular sobre as medidas tomadas e a formulação de políticas no contexto de doenças altamente infecciosas.

${ }^{16}$ Romeo Casabona (Coord.) / Urruela Mora (co-editores) et al., Informe del Ministerio de Sanidad sobre los aspectos éticos en situaciones de pandemia: el SARS-CoV-2,

17 Já SsTC 66/1995, 55/1996 e 207/1996; novas abordagens são adicionadas a partir do STC 136/1999 Concordante em matéria penal STS 3458/2017.
} 
A efetiva execução da medida de acordo com o princípio da proporcionalidade pressupõe o acompanhamento da sua duração, evolução e extinção.

\subsubsection{O princípio da precaução}

O princípio da precaução é geralmente utilizado quando há risco de grandes catástrofes coletivas relacionadas à vida e à saúde das pessoas, e à integridade e sobrevivência de hábitats e ecossistemas de seres vivos (meio ambiente), frequentemente vivenciados como irreversíveis e cujo curso causal não é suficientemente conhecido (qual atividade humana foi, ou pode ser determinante do dano ou efeito catastrófico temido). Pode-se facilmente deduzir que também pode ser de interesse para a proteção da saúde pública e biossegurança e outras necessidades de segurança mais específicas, como emissões eletromagnéticas, radiação de usinas nucleares e outras instalações, centros e ferramentas com capacidade para emiti-las.

Desde a sua criação, este princípio não avançou muito na especificação da sua dimensão jurídica, quer como princípio regulador, orientando a atividade do legislador e da administração pública na tomada de decisões vinculativas para os cidadãos, quer como parte da norma jurídica mesma.

Este princípio foi levado em consideração pela Comissão Europeia diante de certas crises relacionadas com a saúde pública (a epidemia de encefalopatia espongiforme bovina, que poderia ser transmitida ao homem através de príons bovinos contaminados) e levou-a a estabelecer alguns critérios para sua aplicação ${ }^{18}$ : a) avaliação científica do risco, reconhecendo as incertezas, devendo ser atualizada à luz de novas evidências; b) equidade e consistência; c) consideração dos custos e benefícios das ações; d) transparência; e e) proporcionalidade.

Na realidade, o princípio da precaução continua a ser essencialmente uma metodologia de ação e intervenção das autoridades públicas, e não uma norma em si (embora tenhamos exemplos da sua integração normativa e como elemento interpretativo das decisões judiciais). Portanto, pelo menos na situação atual, não consideramos que este princípio possa produzir eficácia aplicativa direta suficiente ${ }^{19}$. Mas faz referência ao princípio da proporcionalidade,

\footnotetext{
${ }^{18}$ Comissão Europeia, Comunicación de la Comisión sobre el principio de precaución, Bruselas, 2000.

${ }^{19}$ Um pouco mais propenso à sua aplicação, mas sem especificar muito suas reais possibilidades de aplicação, é mostrado o Nuffield Council on Bioethics, Public Health: Ethics Issues, Londres, 2007, 35 et seq., Embora prefira chamá-lo de "abordagem preventiva” (precautionary approach), porque considera que é algo diferente de um princípio.
} 
acima defendido, como se viu que a Comissão Europeia propõe, a fim de delimitar melhor os critérios de sua aplicação, como temiam vários sectores industriais, agrícolas e empresariais.

\subsection{Restrição ou privação (suspensão) de direitos individuais e supra-individuais}

A saúde pública é um bem jurídico coletivo, portanto, de propriedade supraindividual; em princípio, a sociedade como tal. Mas é também um bem jurídico instrumental (bem jurídico intermediário) para fazer avançar a intervenção protetora do Direito (no caso, do Direito Penal) e alcançar a proteção de outros bens individuais (vida e saúde individuais) como objetivo final ${ }^{20}$. Ressaltamos aqui apenas que os conceitos de saúde e biossegurança estão intimamente relacionados, o que pode ter relevância jurídica.

As restrições podem afetar - e afetaram - vários direitos fundamentais ou constitucionais $^{21}$. Tem sido frequentemente apontado, especialmente no passado próximo, que o confinamento, isolamento ou enclausuramento de cidadãos afeta a liberdade de circulação (art. $17 \mathrm{CE}$ ) ou a liberdade de movimento para se deslocar sem restrições de um lugar para outro ou para permanecer num determinado local (diferente da quarentena, que se aplica aos suspeitos de estarem infectados e aos já doentes, que também veem este direito fundamental diminuído), bem como à liberdade de residência e circulação (art. $19 \mathrm{CE}$ ). A verdade é que a realidade tem sido bem diferente, pois outros direitos de diferentes naturezas e abrangências também foram restringidos:

* As liberdades de manifestação, que tiveram de ser expressas por meio de vários procedimentos restritos (por exemplo, de varandas e janelas de casas; dentro de veículos em vias públicas) e de reunião (art. $21 \mathrm{CE}$ ).

* O direito à proteção da saúde, que em alguns sistemas jurídicos se identifica com o direito à saúde, enquanto em outros são direitos diferentes e até mesmo diferentes em classificação ${ }^{22}$. Do nosso ponto de vista, a afetação do primeiro deles foi comprometida quando o deslocamento para hospitais e outros centros de saúde não foi autorizado para todas as pessoas que necessitam de tratamento intensivo, ou não foram transferidos para centros não

\footnotetext{
${ }^{20}$ Ley Orgánica 3/1986, de 14 de abril, de Medidas Especiales en Materia de Salud Pública, art. $2^{\circ}$.

${ }^{21}$ CM Flood, B Thomas y K Wilson, Civil Liberties vs. Public Health, en CM Flood et al. (Eds.), Vulnerable. The Law, Policy and Ethics of COVID 19, University of Ottawa Press, 2020, 251 y ss., indicam que, diante das posições opostas existentes, os princípios da proporcionalidade e da precaução podem atuar de forma complementar.

22 Assim, na CE ambos os direitos são claramente distinguidos, os quais também têm uma classificação diferente: o direito à saúde como um direito fundamental (art. 15, embora não seja explicitamente mencionado); e o direito à proteção da saúde, como direito constitucional inferior ao anterior, por não ser um direito fundamental (art. 43.1 CE).
} 
saturados de outras regiões; ou a realização de práticas esportivas habituais ou práticas de exercício (caminhadas) ao ar livre. Têm sido de pouca importância o cancelamento ou adiamento de consultas não urgentes e intervenções relacionadas a outras doenças que não a pandemia, sendo substituídas, quando possível, por consultas telefônicas ou telemáticas, desde que a assistência necessária tenha sido contemplada, inclusive presencial, com internação e intervenção, mesmo cirúrgica ${ }^{23}$, em casos graves.

* O direito ao trabalho e à liberdade de negócios (arts. 35 e $38 \mathrm{CE}$ ), pois, exceto aquelas classificadas como empregos essenciais ou teletrabalho, a população tem sido privada de poder exercer o seu trabalho da forma usual, sem falar o número muito elevado de pessoas que perderam o emprego, sem prejuízo das medidas de compensação paliativa temporária (as chamadas ERTE no nosso país). Além disso, as restrições à atividade laboral e ao desemprego implicam grandes custos e perdas para todos os tipos de empresas e enormes desequilíbrios econômicos dentro dos Estados e organizações supranacionais, como a União Europeia, que se manifesta numa queda drástica do PIB e um aumento muito elevado da dívida pública.

* Os direitos relativos ao consumo e ao lazer (arts. 43, 44 e 51 CE). Afetados pelo encerramento temporário de lojas e centros comerciais, bares e restaurantes, boates, academias, teatros, cinemas e shows, etc.

* O livre exercício dos direitos e relações familiares e matrimoniais (arts. 32 e 39 $\mathrm{CE}$ ), na medida em que famílias efetivamente separadas desde o momento do confinamento ou medidas de enclausuramento ou isolamento semelhantes sejam declaradas; impossibilidade de assistência e ajuda aos familiares doentes ou em risco de infecção por se encontrarem em residências ou outros centros de acolhimento (idosos, deficientes, imigrantes adultos e menores em lares de acolhimento), suspensão da celebração de casamentos.

* A liberdade religiosa no seu exercício comunitário (art. 16 CE). A proibição da celebração de atos religiosos coletivos de culto, como orações e preces, missas, batismos, funerais e sepultamentos e outras práticas religiosas não cristãs, incluindo aquelas de pessoas que morreram como resultado do contágio da doença pandêmica e outros atos religiosos, como procissões, etc.

* O direito à privacidade pessoal e familiar, à vida privada e à proteção dos dados pessoais (art. 18.1 e $4 \mathrm{CE}$ ). A coleta e processamento de dados relacionados à saúde é um componente essencial da luta contra a pandemia COVID-19, incluindo o uso de tecnologias

\footnotetext{
${ }^{23}$ Aparentemente, alguns programas de transplante de órgãos, pelo menos os de rim, foram suspensos durante o estado de emergência. V. www.alcer.org
} 
digitais, big data e inteligência artificial. Não há nada a objetar a esse respeito, pelo contrário, os sistemas jurídicos costumam contemplar exceções ou restrições à proteção especial que os dados de saúde merecem, quando se busca um objetivo epidemiológico. A questão é que também pode ser expressa por meio de medidas de controle de cidadãos suspeitos de estarem infectados (pacientes assintomáticos) ou para determinar a rastreabilidade da fonte de contágio em relação a uma pessoa sabidamente infectada, ao manifestar sintomas da doença (por exemplo, os chamados rastreadores, que geralmente constituem a primeira peça para localizar pessoas infectadas). A utilização de dados não anonimizados sem o consentimento das partes interessadas já constitui uma violação do direito fundamental, embora seja incentivada com o objetivo de combater a pandemia. Não há dúvida de que este objetivo pode ajudar a salvar a vida ou proteger a saúde de muitas pessoas, mas deve mais uma vez estar sujeito ao princípio da proporcionalidade e para este pressuposto, lembraremos o que mencionamos acima de que é estritamente necessário o tratamento de dados pessoais sem o consentimento do interessado ${ }^{24}$, desde que o benefício esperado não possa ser alcançado de outra forma. Não é fácil estabelecer diretrizes mais detalhadas em abstrato.

O Regulamento Geral de Proteção de Dados admite o tratamento de dados em caso de emergência de saúde pública ${ }^{25}$. No entanto, conforme sublinhado na Declaração Conjunta do Conselho da Europa sobre o direito à proteção de dados no contexto da pandemia COVID-19, "a ameaça resultante da pandemia COVID-19 [será tratada] com respeito à democracia, ao estado de direito e aos direitos humanos, incluindo o direito à privacidade e à proteção de

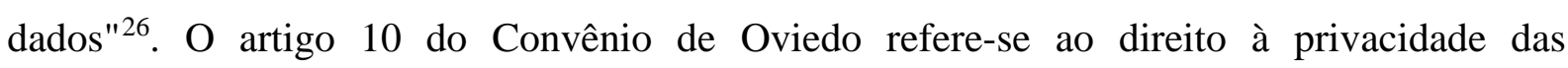
informações na área da saúde, reafirmando assim o princípio introduzido no artigo 8 do Convênio Europeu de Direitos Humanos de 1950. De acordo com o Convênio atualizado para proteção das pessoas no que diz respeito ao tratamento de dados pessoais ${ }^{27}$, recorde-se que os dados relativos à saúde são dados sensíveis, cujo conhecimento ou divulgação coloca os

\footnotetext{
${ }^{24}$ Nuffield Council on Bioethics, Guide to the ethics of surveillance and quarantine for novel coronavirus, 2020, p.1.

${ }^{25}$ De acordo com o considerando 46 do RGPD 2016/679, “certos tipos de tratamento podem responder tanto a razões importantes de interesse público quanto a interesses vitais da parte interessada, como quando o tratamento é necessário para fins humanitários, incluindo o controle de epidemias e sua propagação, ou em situações de emergência humanitária, especialmente no caso de desastres naturais ou de origem humana”.

${ }^{26}$ De acordo com o presidente do Comitê do Convênio 1081 e Proteção de Dados (Convênio para a proteção de pessoas físicas no que diz respeito ao tratamento automatizado de dados pessoais (CETS nº 108), Comissário do Conselho da Europa.

${ }^{27}$ Council of Europe, Convention for the Protection of individuals with regard to the processing of personal data (Convention 108+), art. 6, categorias especiais de dados, incluindo dados genéticos, dados relacionados à saúde ou que possam revelar a origem racial ou étnica das pessoas.
} 
afetados em situação de especial vulnerabilidade e, por conseguinte, o seu processamento está sujeito a condições de proteção específicas e aprimoradas ${ }^{28}$.

A obtenção de dados anonimizados na origem e seu processamento oportuno não oferece considerações jurídicas especiais, nem mesmo a necessidade do consentimento da pessoa de quem provêm, pois, por definição, não se sabe de quem provêm ${ }^{29}$. Este critério mantém-se válido enquanto estes dados se mantiverem anônimos, visto que, como tal, não estão protegidos pelas normas de proteção de dados, uma vez que não são pessoais (não são identificados ou permitem a identificação da pessoa de onde provêm). A questão conflitante surge ao usar dados pessoais, isto é, identificados ou identificáveis, como dados pseudoanonimizados. Nestes casos, é necessário recorrer, mais uma vez, ao princípio da proporcionalidade, para ponderar se a medida a tomar se adapta aos requisitos deste princípio. Na ponderação sobre a concorrência neste princípio, é necessário levar em consideração o lado do interesse sacrificado de que se trata de dados relativos à saúde da pessoa envolvida e que podem ser processados - inclusive sua obtenção - sem o consentimento dela ${ }^{30}$. Em consonância com este princípio, podemos colocar o princípio da minimização de dados nestas situações, o que também é aplicável nestes $\operatorname{casos}^{31}$.

Reflexões semelhantes de natureza jurídica são apresentadas em relação aos controles de geolocalização de portadores de anticorpos de vírus ou pessoas em risco ou que estiveram em contato com pessoas infectadas ${ }^{32}$, pode implicar uma interferência excessiva e até mesmo em alguns casos desproporcional no direito de privacidade pessoal e familiar garantida pelo CE (art. 18.1). A posição dos estados é diversa, em alguns deles esses dados incluem a identificação das pessoas controladas, enquanto em outros as informações obtidas serão anônimas. Embora a primeira posição deva ser rejeitada, na medida em que envolve uma ingerência desproporcional em um direito fundamental, pelo menos enquanto o princípio da proporcionalidade aplicável ao caso concreto não conduza a outra conclusão; o segundo critério, o do anonimato, se feito com garantias técnicas suficientes, não implicaria, pelo

\footnotetext{
${ }^{28}$ De acordo com o RGPD 2016-679, art. 9.1, que inclui, entre outros, dados genéticos, dados biométricos e dados relativos à saúde, sem prejuízo das limitações de sua seção 2; Este Regulamento considera os dados relativos à saúde como "dados pessoais relativos à saúde física ou mental de uma pessoa singular, incluindo a prestação de serviços de saúde, que revelem informação sobre o seu estado de saúde” (art. 4.15).

${ }^{29}$ Nuffield Council on Bioethics, Guide to the ethics of surveillance and quarantine for novel coronavirus, p.1.

${ }^{30}$ De acordo com o considerando 54 do RGPD: "O tratamento de categorias especiais de dados pessoais, sem o consentimento do interessado, pode ser necessário por razões de interesse público no âmbito da saúde pública. Este tratamento deve ser sujeito a medidas adequadas e específicas de modo a proteger os direitos e liberdades das pessoas singulares. [...] Este tratamento dos dados relativos à saúde por razões de interesse público não deve levar a terceiros, como empresários, seguradoras ou bancos, o tratamento dos dados pessoais para outros fins”.

${ }^{31}$ Agencia Española de Protección de Datos, Consulta n ${ }^{\circ}$ 0017/2020, 7.

32 Controles homologados pela Portaria SND/297/2020, do Ministério da Saúde.
} 
menos à primeira vista, um conflito com o direito fundamental. No entanto, devemos lembrar as dúvidas fundadas que atualmente levantam a eficácia dos procedimentos tecnológicos e de outro tipo de anonimização.

\section{O RETORNO À NORMALIDADE}

O retorno à normalidade implica um retorno à situação de pleno exercício dos direitos dos cidadãos, especialmente os fundamentais, existentes antes do início e da expansão da pandemia e das decisões tomadas pelos poderes públicos para combatê-la ou preveni-la, à custa da restrição ou suspensão de tais direitos.

A recuperação da normalidade significa, em última instância, o restabelecimento de todas as condições do estado democrático e social de direito: recuperação das instituições e práticas democráticas (por exemplo, plena atividade do parlamento, a administração da justiça e outros órgãos constitucionais, meios de comunicação, etc.); a cessação da excepcionalidade no procedimento de produção normativa; a recuperação dos direitos sociais mais relevantes, como o direito à educação, o pleno funcionamento da produção agrícola e industrial e a prestação de serviços, etc.

É, portanto, um retorno à normalidade sem quaisquer adjetivos; ou, no máximo, a uma normalidade "normal" - desculpem a tautologia -, em comparação com o apelo de alguns políticos de "novo normal". Esta última expressão sugere que os cidadãos não irão recuperar a situação de exercício não restritivo dos direitos fundamentais e liberdades públicas anteriores à manifestação da pandemia e da imposição de medidas restritivas por parte do poder executivo e/ou legislativo (estado de emergência na Espanha e similares em outros países). O retorno à normalidade implica que, embora a situação social tenha mudado profundamente, o exercício dos direitos e das liberdades será pleno e devem ser buscados os recursos necessários para que isso aconteça.

Essa recuperação plena não significa que o retorno à normalidade não possa ser gradativo, a fim de preservar os interesses da saúde pública, evitando uma nova propagação da pandemia (surtos de casos de contágio) ${ }^{33}$. É o resultado da ponderação de interesses e do princípio da proporcionalidade. Os cidadãos devem estar cientes de que se trata de um processo de gradual recuperação social sob a proteção do estado democrático de direito (pleno

\footnotetext{
${ }^{33}$ Deutscher Ethikrat, Solidarität und Verantwortung in der Corona-Krise, 6 y s., propõe a contínua reavaliação das medidas restritivas da liberdade; quando justificável, sua retirada gradual e a retomada das atividades sociais e econômicas.
} 
funcionamento dos poderes públicos como instituições democráticas e plena vigência do princípio da legalidade). Em todo caso, não deve ser confundida uma eventual gradação necessária na recuperação das instituições e direitos com uma redução indefinida dos mesmos.

Corre-se o risco de haver uma tendência dos poderes públicos a manterem uma “sociedade tutelada”, prolongando-se no que não é comprovado e estritamente necessário as restrições de direitos, como a liberdade de circulação, condição para o exercício de outras direitos fundamentais e direito à privacidade, implementando novos sistemas de controle telemático; Já foram feitas algumas reclamações sobre essas ameaças em relação às decisões das autoridades públicas de alguns países. Mais uma vez, o princípio da proporcionalidade configura-se como um instrumento jurídico essencial para conter possíveis desvios do poder público.

Em todo o caso, estando cientes de que uma situação tão extraordinária e avassaladora como esta pandemia geralmente justifica as medidas que têm sido tomadas pelos governos dos Estados, devem também estar cientes dos poderes excepcionais e também extraordinários que são outorgados pelas constituições políticas no âmbito do estado de direito, razão pela qual devem ser usados com a maior prudência. E os parlamentos devem garantir que assim seja, independentemente de outras considerações políticas. Uma situação tão grave como a que vivemos não pode justificar a falência ou o enfraquecimento do Estado Democrático de Direito.

\section{UMA BREVE REFLEXÃO SOBRE O FUTURO}

Não seria necessário insistir que uma grande pandemia como esta suscita muitas reflexões sobre como lidar com ela, mas, sobretudo como prevenir esta e outras semelhantes que poderão ocorrer no futuro. Aqui, o Direito enfatiza seu papel fundamentalmente instrumental e secundário com relação a como levar o futuro a sério. Entre outras razões, porque parece que as medidas que devem ser adotadas são de natureza diversa, sem prejuízo da sua constante sujeição ao princípio da legalidade.

Com efeito, esta pandemia e outras com características semelhantes (devido à sua elevada capacidade expansiva, devido ao seu grave prognóstico em muitos casos, as sequelas pós-doença que ainda continuam a ser avaliadas e a falta de recursos para tratar ou prevenir a doença) produzidas no passado mais recente exigem um estudo mais aprofundado. Elas também têm em comum sua origem viral e que seu habitat natural parecem ser animais (especialmente mamíferos, mas também outros vertebrados, como pássaros), que geralmente 
não atacam ou o fazem de forma benigna. Ou seja, em casos conhecidos, houve um salto filogenético interespécies (de animal para humano).

É necessário criar um programa de pesquisas científicas relacionadas a esses tipos de doenças, em nível global, talvez coordenado pela OMS (já houve uma iniciativa semelhante há alguns anos, mas sem uma implementação notável), ou pelo menos no marco da Comunidade Europeia, a fim de melhor compreender a origem de todas elas e as vias de transmissão; configurar infraestruturas de prevenção no âmbito da saúde pública. Os poderes públicos e os cidadãos devem estar cientes de que é necessário mudar alguns comportamentos dos cidadãos, relacionados com a biossegurança, a sustentabilidade e a manutenção dos ecossistemas e dos seus equilíbrios internos. Da mesma forma, o relacionamento interpessoal deve sofrer certas adaptações inspiradas na segurança e na prevenção.

Do ponto de vista jurídico, este tipo de reflexões sobre ações globais conjuntas no campo científico e da saúde poderia ter uma reflexão paralela no que diz respeito aos instrumentos jurídicos internacionais voltados para o combate ou prevenção de pandemias. Sem poder ir mais longe neste ponto, vislumbram-se imediatamente os problemas que geraria a aplicação dos instrumentos jurídicos com âmbito universal para assegurar o seu cumprimento sem restrições ou desvios.

\section{RECOMENDAÇÕES}

Mais uma vez, as recomendações do EGE dirigidas aos Estados-membros da UE devem ser recordadas. Sintetizam a expressão daquilo que a UE deve continuar a ser a partir dos seus princípios fundamentais, para que a credibilidade de milhões de cidadãos europeus não seja desiludida. É claro que as compartilhamos plenamente, mas a insistência em defender sua validade se reforça nos tempos presentes e futuros, nos quais uma falência parece se reabrir no que deveriam ser interesses comuns e compartilhados de todos os estados-membros da $\mathrm{UE}^{34}$ :

1. A proteção da saúde humana tem uma prioridade muito mais elevada no sistema de valores da UE do que os interesses econômicos. Os estados-membros da UE devem, em conjunto, procurar proteger a saúde dos cidadãos da UE e ajudar a fortalecer e manter a integridade dos sistemas de saúde e de outras infraestruturas públicas.

34 EGE, Statement on European Solidarity and the Protection of Fundamental Rights in the COVID-19 Pandemic. 
2. As medidas tomadas por muitos governos para fornecer assistência financeira imediata e outro tipo de apoio a indivíduos, famílias e empresas na comunidade devem continuar e serem fortalecidas, e sugerimos que medidas adicionais sejam tomadas para melhorar a segurança da habitação, especialmente em toda a Europa.

3. Os Estados-membros que dispõem de recursos suficientes para os cuidados de saúde devem partilhar os seus recursos com aqueles que não dispõem dos recursos necessários numa atitude de solidariedade.

4. Salvar vidas é o objetivo mais importante e urgente. As restrições aos direitos e liberdades que são impostas para salvar vidas em uma situação de emergência - incluindo aquelas feitas por vigilância tecnológica por meio de telefonia móvel e dispositivos como drones e câmeras de vigilância - devem, no entanto, ser apagados, e os dados devem ser destruídos, assim que a emergência terminar. A emergência de saúde pública não deve ser aproveitada para usurpar o poder ou para suspender permanentemente a proteção de direitos e liberdades.

5. Uma vez superada a crise, as sociedades europeias devem colaborar para aplicar as lições aprendidas durante a COVID-19. Uma estratégia comum para lidar com uma pandemia e ameaças semelhantes deve ser desenvolvida e implementada a nível europeu e global. Qualquer estratégia deve levar em consideração não apenas as ameaças à saúde, mas também as ameaças às nossas democracias, aos direitos individuais e à sustentabilidade econômica. A COVID-19 mostrou, mais uma vez, que os mais desfavorecidos socioeconomicamente são os mais vulneráveis a doenças e enfermidades. 